\title{
ANALIS KESTABILAN LERENG PADA LOKASI TAMBANG BATUBARA TANAH LAUT KALIMANTAN SELATAN
}

\section{SLOPE STABILITY ANALYSIS ON COAL MINE LOCATIONS IN TANAH LAUT SOUTH BORNEO}

\author{
Teddy Wartono Sudinda ${ }^{1}$ \\ ${ }^{1}$ Pusat Teknologi Lingkungan (PTL) - BPPT \\ Gedung 820, GEOSTECH, PUSPIPTEK, Kota Tangerang Selatan, telepon: (021) 75791378 \\ e-mail: teddy.sudinda@bppt.go.id
}

\begin{abstract}
The stability of the slopes at the location of the South Borneo marine ground coal mine has been analyzed by stress-displacement and safety factor (SF) using the Plaxis-2D program. On the slope surface, the component of gravity acting on the ground tends to move the ground down. This component of gravity is known as the ground driving force. Slopes have natural reinforcement that comes from the components of the soil material itself to counteract the driving force of the soil, so that soil movements or landslides do not occur. There are many analytical methods that can be used in analyzing slope stability, one of which is the Finite Element Method. Slope stability problems are solved by the Finite Element Method using Plaxis $2 D$ program, where the analysis data is obtained from the results of previous studies. The analysis data is a combination of various analytical data, namely soil type and slope. The results of the previous analysis using the Slope-W program for the East Section (SW Section), West Section (SW Section), East HW Section (NS Section), East LW Section (NS Section) obtained a collapse model with the safety number $S F<1.0$ and compared with analysis using Plaxis-2D, where the safety value SF $<1$ could not be determined. Based on the Slope-W analysis, the SF value $<1.0$ (0.114) and the Plaxis analysis, the $S F<1$ value occurs in the East Section (SW Section), this shows that the analysis with the Slope-W program and the Plaxis-2D program have the same results in determining the possibility of a collapse.
\end{abstract}

Keywords: slope stability, finite element method, safety factor

\begin{abstract}
ABSTRAK
Kestabilan lereng di lokasi tambang batubara tanah laut Kalimantan Selatan telah dilakukan analisis tegangan-perpindahan dan Faktor Keamanan (SF) dengan menggunakan program Plaxis-2D. Pada permukaan lereng komponen gravitasi yang bekerja pada tanah cenderung akan menggerakkan tanah ke bawah. Komponen gravitasi ini disebut sebagai gaya penggerak tanah. Lereng mempunyai perkuatan alami yang berasal dari komponen material tanah itu sendiri untuk melawan gaya penggerak tanah, sehingga gerakan tanah atau kelongsoran tidak terjadi. Ada banyak metode analisis yang bisa digunakan dalam menganalisis kestabilan lereng, salah satunya adalah dengan menggunakan Metode Elemen Hingga (Finite Element Method). Permasalahan kestabilan lereng diselesaikan dengan Metode Elemen Hingga dengan menggunakan program Plaxis 2D, dimana data analisis diperoleh dari hasil penelitian terdahulu. Data analisis merupakan kombinasi dari berbagai data analisis yaitu jenis tanah dan kemiringan lereng. Hasil analisis terdahulu dengan menggunakan program Slope-W untuk Potongan East (S-W Section), Potongan West (S-W Section), Potongan East HW (N-S Section), Potongan East LW (N-S Section) diperoleh model keruntuhan (collapse) dengan angka keamanan $\mathrm{SF}<1$, dan dibandingkan dengan analisis menggunakan Plaxis-2D, dimana nilai angka keamanan $S F<1$ tidak bisa ditentukan. Berdasarkan analisis Slope-W diperoleh nilai SF $<1,0(0,114)$ dan analisis Plaxis diperoleh nilai SF $<1$ terjadi pada Potongan East ( $S-W$ Section), hal ini menunjukkan bahwa analisis dengan program Slope-W dan program Plaxis $2 \mathrm{D}$ mempunyai hasil yang sama dalam menentukan kemungkinan akan terjadi keruntuhan.
\end{abstract}

Kata kunci: kestabilan lereng, metode elemen hingga, faktor keamanan 


\section{PENDAHULUAN}

Stabilitas lereng lahan rencana tambang mempunyai kaitan erat dengan perkembangan bidang diskontinuitas yang berkembang pada massa batuan penyusun daerah studi. Keberadaan litologi yang disusun oleh batuan sedimenter, struktur geologi yang ditemukan berkembang sebagai sesar dan kondisi lereng mikro yang setempat masih tampak relatif terjal sangat mempengaruhi kondisi stabilitas lahan daerah studi. Daerah studi yang membujur pada arah barat daya - timur laut disusun oleh batuan sedimenter Formasi Tanjung. Formasi Tanjung disusun oleh litologi konglomerat, batupasir kuarsa, batulempung dengan sisipan batubara di bagian bawah dan batupasir, siltstone serta batulempung (mudstone) di bagian atas.

Berdasarkan hasil observasi di lokasi tambang, terdapat beberapa longsoran kecil yang hampir terjadi di setiap pit tambang, namun pada umumnya lereng dinding tambang pada kondisi stabil. Kondisi stabilitas lereng pada daerah sekitar tambang khususnya daerah topografi bergelombang termasuk wilayah pemukiman penduduk masih dalam kondisi aman dan stabil, ditunjang dengan masih baiknya kondisi vegetasi mempunyai kontribusi yang cukup berarti untuk menunjang kemantapan lereng daerah setempat. Kondisi lereng di luar wilayah penambangan yang tidak stabil hanya dapat ditemukan secara setempat di lereng sungai di pinggir S. Kintap dan S. Satui yaitu berupa runtuhan tanah yang dipicu oleh adanya erosi lateral sungai.

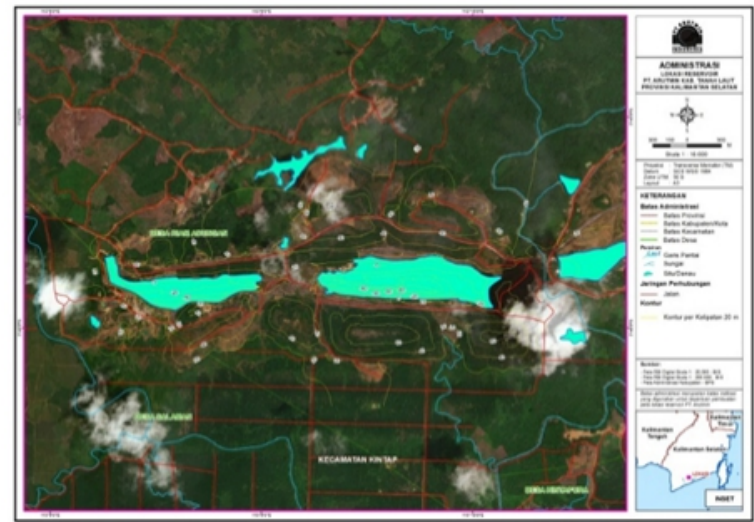

Gambar 1. Lokasi Reservoir Antasena PT. Arutmin

Untuk menyelesaikan permasalahan stabilitas lereng maka perlu tinjauan yang lebih mendalam tentang stabilitas lereng. Stabilitas lereng merupakan suatu faktor yang sangat penting dalam pekerjaan yang berhubungan dengan penggalian dan penimbunan tanah, batuan, dan bahan galian.

Dalam operasi penambangan masalah kemantapan lereng ini akan diketemukan pada penggalian tambang terbuka, bendungan untuk cadangan air kerja, tempat penimbunan limbah buangan (tailing disposal) dan penimbunan bijih (stockyard). Apabila lereng-lereng yang terbentuk sebagai akibat dari proses penambangan (pitslope) maupun yang merupakan sarana penunjang operasi penambangan (seperti bendungan dan jalan) tidak stabil, maka akan mengganggu kegiatan produksi. Para peneliti terdahulu telah melakukan kajian terkait dengan kestabilan lereng bekas tanah urug di Kota Banjar Baru (Dwiatmoko et.al., 2020), kajian stabillitas lereng pada tambang terbuka bahan galian C (Solihin dan Raditia, 2016), kajian kestabilan lereng pada tambang batubara terbuka Pit D (Bria dan Isjudarto. 2016 )

Dari keterangan di atas, dapat dipahami bahwa analisis kemantapan lereng merupakan suatu bagian yang penting untuk mencegah terjadinya gangguan terhadap kelancaran produksi maupun terjadinya bencana yang fatal. Dalam keadaan tidak terganggu (alamiah), tanah atau batuan umumnya berada dalam keadaan seimbang terhadap gaya-gaya yang timbul dari dalam. Kalau misalnya karena sesuatu sebab mengalami perubahan keseimbangan akibat pengangkatan, penurunan, penggalian, penimbunan, erosi atau aktivitas lain, maka tanah atau batuan itu akan berusaha untuk mencapai keadaaan yang baru secara alamiah. Cara ini biasanya berupa proses degradasi atau pengurangan beban, terutama dalam bentuk longsoran-longsoran atau gerakan-gerakan lain sampai tercapai keadaaan keseimbangan yang baru.

Pada tanah atau batuan dalam keadaan tidak terganggu (alamiah) telah bekerja tegangan-tegangan vertikal, horisontal dan tekanan air dari pori. Ketiga hal di atas mempunyai peranan penting dalam membentuk kestabilan lereng. Sedangkan tanah atau batuan sendiri mempunyai sifat-sifat fisik asli tertentu, seperti sudut geser dalam (angle of internal friction), gaya kohesi, dan bobot isi yang juga sangat berperan dalam menentukan kekuatan tanah dan yang juga mempengaruhi kemantapan lereng. Oleh karena itu, dalam usaha untuk melakukan analisis kemantapan lereng harus diketahui dengan pasti sistem tegangan yang bekerja pada tanah atau batuan dan juga sifat-sifat fisik aslinya. Dengan pengetahuan dan data tersebut kemudian dapat dilakukan analisis kelakuan tanah atau 
batuan tersebut jika digali atau "diganggu". Setelah itu, bisa ditentukan geometri lereng yang diperbolehkan atau mengaplikasikan cara-cara lain yang dapat membantu lereng tersebut menjadi stabil dan mantap. Untuk penyelesaian kestabilan lereng peneliti terdahulu telah melakukan analisis dengan menggunakan Metode Elemen Hingga untuk mendapatkan Faktor Keamanan agar tidak terjadi longsor (Wibowo et al., 2018, Nuryanto dan Wulandari, 2017).

Penulis dalam makalah ini melakukan analisis kestabilan lereng pada lokasi reklamasi tanggul reservoir akibat penambangan batubara yang dianggap rentan terhadap longsor dengan menggunakan program Plaxis2D yang selanjutnya dibandingkan dengan program Slope-W yang keduanya menggunakan Metode Elemen Hingga (Finite Element Method).

\section{METODOLOG}

Suatu longsoran adalah keruntuhan dari massa tanah yang terletak pada sebuah lereng sehingga terjadi pergerakan massa tanah ke bawah dan ke luar. Longsoran dapat terjadi dengan berbagai cara, secara perlahan-lahan atau mendadak serta dengan ataupun tanpa tanda-tanda yang terlihat. Setelah gempa bumi, longsoran merupakan bencana alam yang paling banyak mengakibatkan kerugian materi maupun kematian. Kerugian dapat ditimbulkan oleh suatu longsoran antara lain yaitu rusaknya lahan pertanian, rumah, bangunan, jalur transportsi serta sarana komunikasi.

Analisis kestabilan lereng harus berdasarkan model yang akurat mengenai kondisi material bawah permukaan, kondisi air tanah dan pembebanan yang mungkin bekerja pada lereng. Tanpa sebuah model geologi yang memadai, analisis hanya dapat dilakukan dengan menggunakan pendekatan yang kasar sehingga kegunaan dari hasil analisis dapat dipertanyakan.

Metode Fellenius (Ordinary Method of Slice) diperkenalkan pertama oleh Fellenius $(1927,1936)$ berdasarkan bahwa gaya memiliki sudut kemiringan paralel dengan dasar irisan FK dihitung dengan keseimbangan momen. Fellenius mengemukakan metodenya dengan menyatakan asumsi bahwa keruntuhan terjadi melalui rotasi dari suatu blok tanah pada permukaan longsor berbentuk lingkaran (sirkuler) dengan titik $\mathrm{O}$ sebagai titik pusat rotasi. Metode ini juga menganggap bahwa gaya normal $\mathrm{P}$ bekerja di tengah-tengah slice (Violeta et al., 2014; Tinambunan et al., 2018).
Dengan anggapan-anggapan ini maka dapat diuji persamaan keseimbangan momen untuk seluruh irisan terhadap titik pusat rotasi dan diperoleh suatu nilai faktor keamanan. Pada Gambar 2 diperlihatkan suatu lereng dengan sistem irisan untuk berat sendiri massa tanah (W) serta analisis komponen gaya-gaya yang timbul dari berat massa tanah tersebut, yang terdiri dari gaya-gaya antar irisan yang bekerja di samping kanan irisan ( $\mathrm{Er}$ dan $\mathrm{Xt}$ ). Pada bagian alas irisan, gaya berat (W) diuraikan menjadi gaya reaksi normal $\mathrm{Pw}$ yang bekerja tegak lurus alas irisan dan gaya tangensial Tw yang bekerja sejajar irisan. Besarnya lengan gaya (W) adalah $x=R \sin \alpha$, dimana $R$ adalah jari-jari lingkaran longsor dan sudut $\alpha$ adalah sudut pada titik $O$ yang dibentuk antara garis vertikal dengan jari-jari lingkaran longsor.

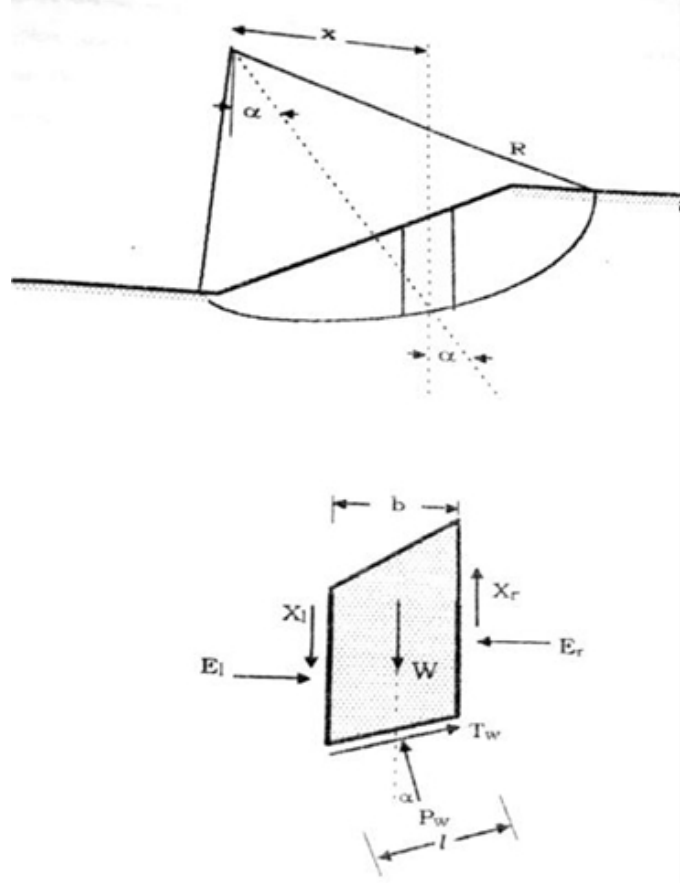

Gambar 2. Lereng Dengan Busur Lingkaran Bidang Longsor (Violeta et al., 2014)

Dalam menentukan kestabilan atau kemantapan lereng, dikenal istilah faktor keamanan (safety factor) yang merupakan perbandingan antara gaya-gaya yang menahan gerakan terhadap gaya-gaya yang menggerakkan tanah tersebut dianggap stabil, bila dirumuskan sebagai berikut :

Faktor kemanan $(F)$ = gaya penahan / gaya penggerak

Dimana untuk keadaan: 
- $F>1,250$

aman

: lereng dalam keadaan

$\bullet 1,000<\mathrm{F}<1,250$ : lereng dalam keadaan seimbang, dan siap untuk longsor

- $\mathrm{F}<1,000 \quad$ : lereng tidak aman

\subsection{Angka Keamanan Plaxis (Phi-c Reduction)}

Analisis keamanan dalam PLAXIS dapat dilakukan dengan mereduksi parameter kekuatan dari tanah yang disebut sebagai Reduksi phi-c. Reduksi phi-c digunakan untuk menghitung faktor keamanan global dalam analisis tertentu. Analisis keamanan dapat dilakukan di setiap tahapan perhitungan ataupun tahapan konstruksi secara individual. Namun, tahapan Reduksi phi-c tidak dapat kembali ke kondisi awal untuk tahapan perhitungan yang lain karena tahapan Reduksi phi-c berakhir pada suatu kondisi keruntuhan.

Pada saat melakukan suatu analisis keamanan, peningkatan pembebanan tidak dapat dilakukan secara simultan karena Reduksi phi-c pada dasarnya merupakan suatu jenis perhitungan plastis yang khusus. Kekuatan dari interface, jika digunakan, juga direduksi dengan cara yang sama. Kekuatan dari struktural seperti pelat dan jangkar tidak dipengaruhi oleh Reduksi phi-c.

Saat menggunakan Reduksi phi-c dengan model-model tanah tingkat lanjut, maka model-model tersebut akan berlaku sebagai model Mohr-Coulomb standar, karena sifat kekakuan yang tergantung dari tegangan dan efek hardening tidak ikut diperhitungkan dalam analisis. Sehingga kekakuan yang digunakan adalah kekakuan yang dihitung pada awal tahapan perhitungan dan tetap bernilai konstan hingga tahapan perhitungan selesai.

Faktor pengali total $\Sigma$ Msf digunakan untuk mendefinisikan parameter kekuatan tanah pada suatu tahapan tertentu dalam analisis, yaitu:

$$
\sum M s f=\frac{\tan \emptyset_{\text {masukan }}}{\tan \emptyset_{\text {reduksi }}}=\frac{c_{\text {masukan }}}{c_{\text {reduksi }}}
$$

Nilai $\Sigma$ Msf diatur ke 1,0 pada awal perhitungan agar seluruh kekuatan material diatur ke nilai yang belum direduksi. Faktor keamanan yang diberikan adalah:

$F K=\frac{\text { Kekua tan yang tersedia }}{\text { Kekua tan saat runtuh }}=$ nilai $\Sigma M s f$ saat runtuh

\subsection{Pengertian dan Konsep Dasar Metode Elemen Hingga (Finite}

Finite Element Method (FEM) atau biasanya disebut Finite Element Analysis (FEA), adalah prosedur numeris yang dapat dipakai untuk menyelesaikan masalahmasalah dalam bidang rekayasa (engineering). Inti dari FEM adalah membagi suatu benda yang akan dianalisis, menjadi beberapa bagian dengan jumlah hingga (finite). Bagianbagian ini disebut elemen yang tiap elemen satu dengan elemen lainnya dihubungkan dengan nodal (node). Kemudian dibangun persamaan matematika yang menjadi reprensentasi benda tersebut. Proses pembagian benda menjadi beberapa bagian disebut meshing yang menggambarkan dasar pendekatan FEM yang dijelaskan pada Gambar 3.

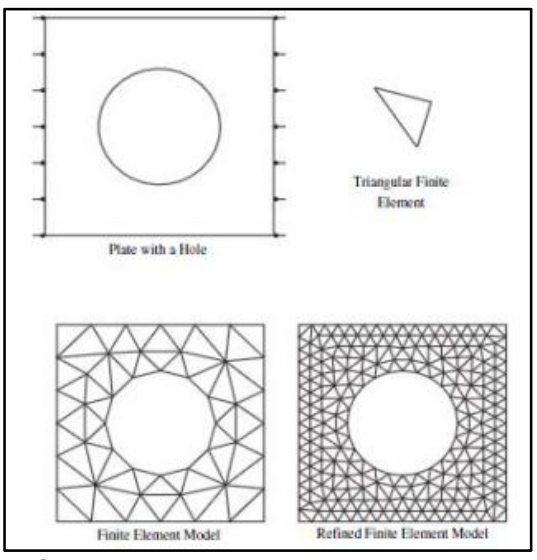

Gambar 3. Meshing pada Plate

Sumber: A First Course in Finite Elements. Jacob and Belytschko (2007)

Banyak fenomena fisik dalam bidang sains dan teknik yang dapat digambarkan dalam bentuk persamaan diferensial parsial. Secara umum, memecahkan persamaan ini dengan metode analitis klasik untuk bentuk atau pola yang acak sangat sulit dan hampir mustahil. Metode elemen hingga (FEM) adalah salah satu metode pendekatan numerik di mana persamaan diferensial parsial. Penyelesaian dengan menggunakan Metode Elemen Hingga (FEM) menghasilkan sebuah persamaan dari suatu masalah yang kemudian akan dianalisis dalam suatu sistem persamaan serentak agar diperoleh suatu penyelesaian. Penyelesaian dengan metode elemen hingga tersebut akan memberikan suatu hasil pendekatan dari nilai sebenarnya yang tidak diketahui pada suatu titik tertentu dalam sistem kontinyu. Sistem yang kontinyu merupakan istilah dari suatu kondisi struktur atau objek yang sebenarnya. Dikritisasi (discretization) merupakan proses pemodelan dari suatu objek 
dengan membagi ke dalam elemen-elemen kecil (finite element) yang dihubungkan oleh titik-titik (nodes) yang digunakan oleh elemenelemen tersebut dan juga sebagai batasan dari objek tersebut. $\mathrm{Di}$ dalam metode elemen hingga persamaan yang diperoleh dari seluruh sistem kemudian dibentuk dari penggabungan persamaan elemen-elemennya.

Penyelesaian suatu masalah dengan Metode Elemen Hingga (MEH) umumnya menggunakan perhitungan matriks yang cukup kompleks. Penyelesaian MEH memerlukan perhitungan yang cukup banyak dan berulang, sehingga diperlukan program komputer untuk mempermudah dan juga agar lebih efisien. Penyelesaian dari seluruh sistem biasanya merupakan persamaan serentak dan dinyatakan dalam bentuk matriks kemudian diselesaian menggunakan persamaan serentak seperti Iterasi Gauss-Seidel, Cholesky, dan Eliminasi Gauss.

Prosedur pembuatan model secara grafis yang mudah memungkinkan pembuatan suatu model elemen hingga yang rumit dapat dilakukan dengan cepat, sedangkan berbagai fasilitas yang tersedia dapat digunakan untuk menampilkan hasil komputasi secara mendetil. Proses perhitungannya sendiri sepenuhnya berjalan secara otomatis dan didasarkan pada prosedur numerik yang handal (PLAXIS Versi 8.2, Geotechnical Software, 2002, Delft Netherland).

\section{HASIL ANALISIS KESTABILAN LERENG}

Berdasarkan data sekunder hasil penyelidikan geoteknik diketahui bahwa Pit Tambang berpotensi menyebabkan terjadinya longsoran. Hal ini terbukti dengan adanya longsoran-longsoran kecil di setiap pit tambang. Dari hasil penyelidikan geoteknik diketahui pula bahwa di setiap pit tambang mempunyai nilai Faktor Keamanan $(F K) \geq 1,320$, yakni nilai yang mengindikasikan bahwa lereng dinding tambang Pit Satui dan Karuh dalam kondisi aman (Tabel 1).

Tabel 1. Faktor Keamanan (FK) Pit Tambang di Wilayah Studi.

\begin{tabular}{l|l|l|l}
\hline No. & PIT & $\begin{array}{l}\text { Jenis } \\
\text { Material }\end{array}$ & Nilai FK \\
\hline 1 & \multirow{2}{*}{ Antasena } & Mudstone & 1,320 \\
\cline { 3 - 4 } & & Siltstone & 1,433 \\
\cline { 3 - 4 } & & Sandstone & 1,731 \\
\hline
\end{tabular}

\begin{tabular}{|c|c|c|c|}
\hline & & Batubara & 4,370 \\
\hline \multirow[t]{4}{*}{2} & \multirow[t]{4}{*}{ Yidistira } & Mudstone & 1,336 \\
\hline & & Siltstone & 2,785 \\
\hline & & Sandstone & 2,279 \\
\hline & & Batubara & 4,370 \\
\hline \multirow[t]{4}{*}{3} & \multirow[t]{4}{*}{ Kresna } & Mudstone & 4,197 \\
\hline & & Siltstone & 10,003 \\
\hline & & Sandstone & 2,556 \\
\hline & & Batubara & 4,643 \\
\hline \multirow[t]{4}{*}{4} & \multirow[t]{4}{*}{ Gatotkaca } & Mudstone & 1,350 \\
\hline & & Siltstone & 1,410 \\
\hline & & Sandstone & 1,340 \\
\hline & & Batubara & 2,180 \\
\hline \multirow[t]{4}{*}{5} & \multirow[t]{4}{*}{ Antareja } & Mudstone & 1,350 \\
\hline & & Siltstone & 1,320 \\
\hline & & Sandstone & 1,330 \\
\hline & & Batubara & 20,462 \\
\hline
\end{tabular}

Sumber : PT Arutmin Indonesia 2004 (Laporan Studi Kemantapan Lereng).

Berdasarkan analisis kestabilan lereng yang dilakukan oleh konsultan Satui Engineering untuk Void Antasena timur yang memiliki luas 46,7 ha dan kedalaman $96 \mathrm{~m}$. Meterial Properties terdiri dari waste, sandstone, siltstone, claystone, carbonaceous, Coal dan bed rock yang mempunyai properties nilai Unit Weigth, Cohesion dan Phi dapat dilihat pada Tabel 2.

Tabel 2. Parameter Tanah Void Antasena

\begin{tabular}{|c|c|c|c|}
\hline Material & $\begin{array}{c}\text { Unit } \\
\text { Weigth }\end{array}$ & $\begin{array}{c}\text { Cohesion } \\
\text { (kPa) }\end{array}$ & $\begin{array}{l}\text { Phi } \\
\text { (0) }\end{array}$ \\
\hline Waste & 18 & 8 & 32 \\
\hline Sandstone & 23,7 & 283 & 34,8 \\
\hline Siltstone & 21,9 & 177 & 28,12 \\
\hline Claystone & 21,3 & 137 & 24,9 \\
\hline $\begin{array}{l}\text { Carbonaceou } \\
s\end{array}$ & 21,2 & 82 & 17,43 \\
\hline Coal & 12,9 & 358 & 47 \\
\hline Bed Rock & Inpenetrabl & Inpenetrabl & Inpenetrabl \\
\hline
\end{tabular}




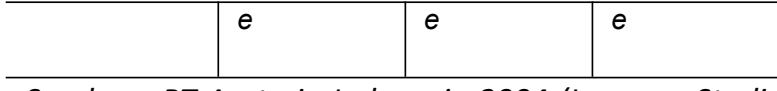

Sumber : PT Arutmin Indonesia 2004 (Laporan Studi Kemantapan Lereng).

Analisis dilakukan pada kondisi jenuh dan $90 \%$ jenuh. Besarnya faktor keamanan (safety factor) ditentukan atas dasar nilai SF > 1,250 kondisi aman, nilai SF antara 1,000 1,250 kondisi kritis dan nilai SF $<1,000$ kondisi tidak aman. Void Antasena untuk dilakukan pengecekan stabilitasnya kondisi saat ini ditunjukkan pada Gambar 4.

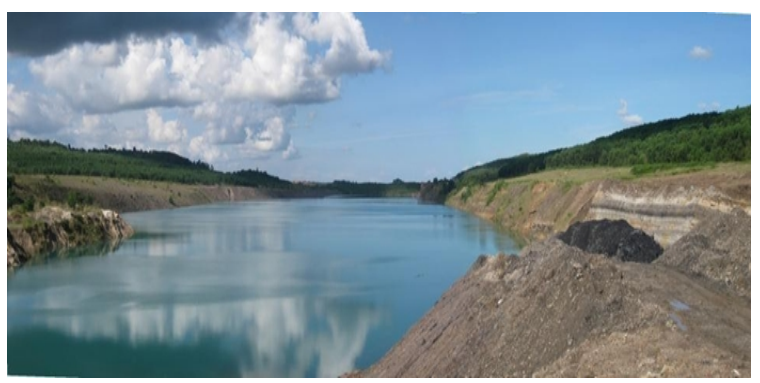

Gambar 4. Situasi Reservoir Antasena

Lokasi lereng yang perlu dilakukan pengecekan terdiri dari 2 bagian yaitu East (daerah yang lebih landai) dan West (daerah yang lebih curam). Lereng tersebut telah dihitung menggunakan slope-W dan hasil untuk Slope S-W Potongan East (S-W Section) SF = 0,114 dapat dilihat pada Gambar 5, dan hasil Slope S-W Potongan West (S-W Section) SF = 1,743 dapat dilihat pada Gambar 6. Slope S-W Potongan East HW (N-S Section) SF = 1,258 dapat dilihat pada Gambar 7 dan Slope S-W Potongan East LW (N-S Section) SF $=1,33$ dapat dilihat pada Gambar 8 dan hasil perhitungan ditunjukkan pada Tabel 4. Pada dasarnya angka keamanan lereng merupakan perbandingan antara kekuatan tanah yang menahan dengan yang mendorong lereng tersebut. Artinya dengan angka keamanan $S F=1,0$ (kondisi kritis) lereng masih bisa berdiri. Namun untuk kasus potongan B-B, dari analisis slope-W diperoleh angka keamanan $<1,0$, dimana lereng seharusnya sudah longsor.

Tabel 4. Angka Keamanan Slope-W

\begin{tabular}{c|c}
\hline Potongan Melintang & Kondisi Jenuh \\
\hline$A$ (East SW) & 1,743 \\
\hline$B$ (West SW $)$ & 0,114 \\
\hline$A$ (HW Area) & 1,258 \\
\hline$B(L W$ Area $)$ & 0,521 \\
\hline
\end{tabular}

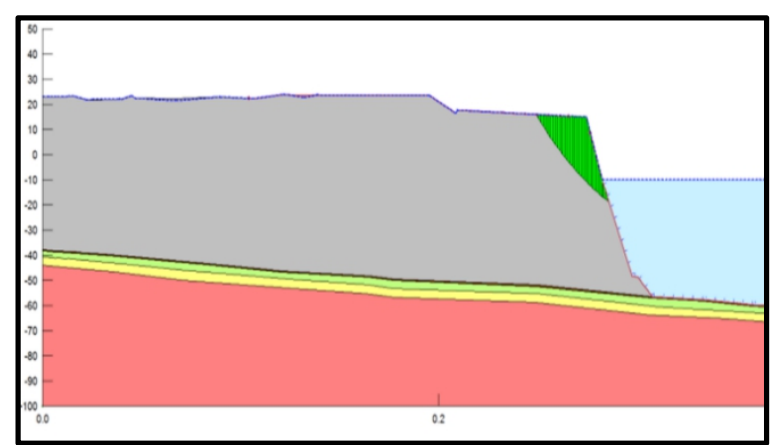

Gambar 5. Hasil Slope S-W Potongan East (SW Section) SF $=0,114$

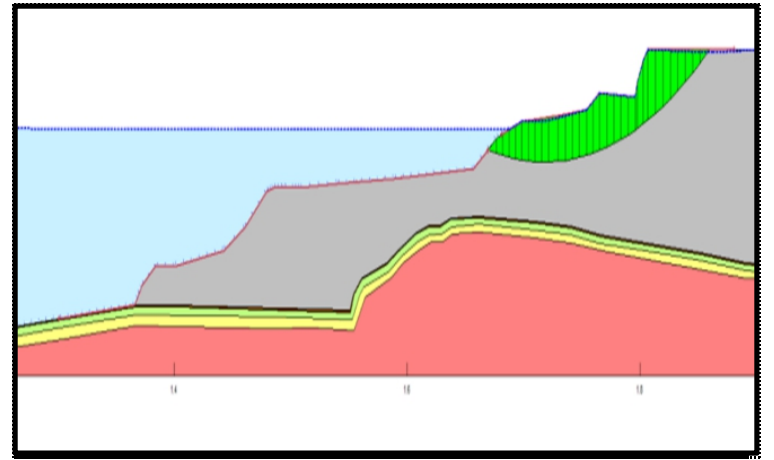

Gambar 6. Hasil Slope S-W Potongan West (S-W Section) SF $=1,743$

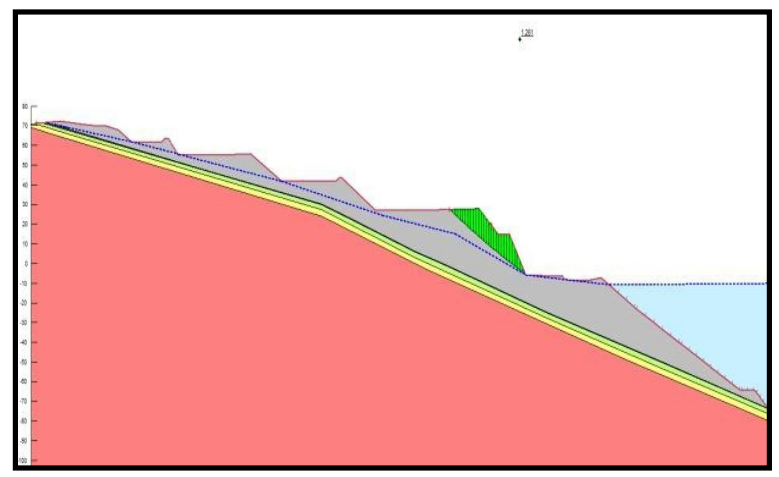

Gambar 7. Hasil Slope S-W Potongan East HW (N-S Section) SF $=1,258$

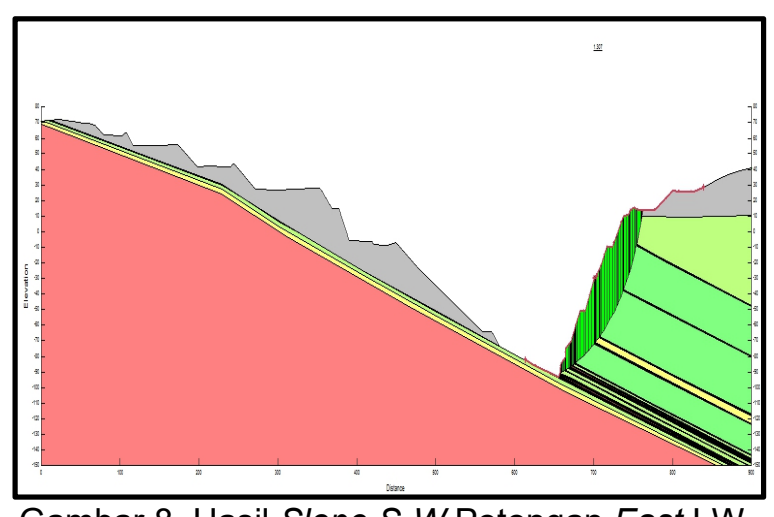

Gambar 8. Hasil Slope S-W Potongan East LW (N-S Section) SF = 1,33 


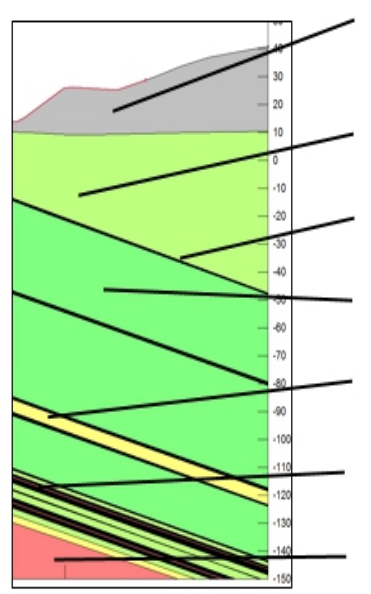

\section{Waste (Abu-abu)}

Claystone (Hjau muda)

Coal (Hitam)

Siltstone (Hjiau tua)

Sandstone (Kuning)

Carbonaceous Mudstone (Coklat)

Impenetrable Bedrock (Pink)

Gambar 9. Jenis Lapisan Tanah

Plaxis merupakan program komputer berdasarkan metode elemen hingga ( 2 dan 3 Dimensi) yang dapat digunakan secara khusus melakukan analisis deformasi dan stabilitas untuk bebagai aplikasi dalam bidang geoteknik. Program ini merupakan metode antarmuka grafis yang mudah digunakan sehingga pengguna dapat dengan cepat membuat model geometri dan jaring elemen berdasarkan penampang melintang dari kondisi lereng yang akan dianalisis. Angka keamanan diperoleh dari hasil perhitungan Plaxis merupakan angka keamanan secara global terhadap model. Perlu diperhatikan bahwa analisis ini tidak diikutsertakan muka air tanah.

\section{Potongan East (S-W Section)}

Section S-W dibagi atas dua potongan yaitu pada bagian east, dimana lereng lebih curam dan timbunan (waste) lebih tebal dan kedua adalah potongan west dengan kondisi lereng cukup landai. Model perhitungan yang digunakan adalah model keruntuhan MohrCoulomb, dengan spesifikasi perilaku tanah drained pada lapisan pasir dan undrained pada lapisan lempung/lanau.

Hasil perhitungan untuk potongan East SF $<1,0$ dimana lereng sudah mengalami keruntuhan. Daerah paling kritis berada pada kaki lereng. Keruntuhan terjadi pada lapisan waste yang mempunyai parameter kekakuan dan kekuatan tanah lebih kecil dari lapisan lainnya. Hasil perhitungan ditunjukkan pada Gambar 10, sedangkan pada potongan West angka keamanan diperoleh sebesar $\mathrm{SF}=2,34$, dimana lereng cukup kuat karena lapisan waste cukup landai. Hasil perhitungan plaxis ditunjukkan pada Gambar 11.

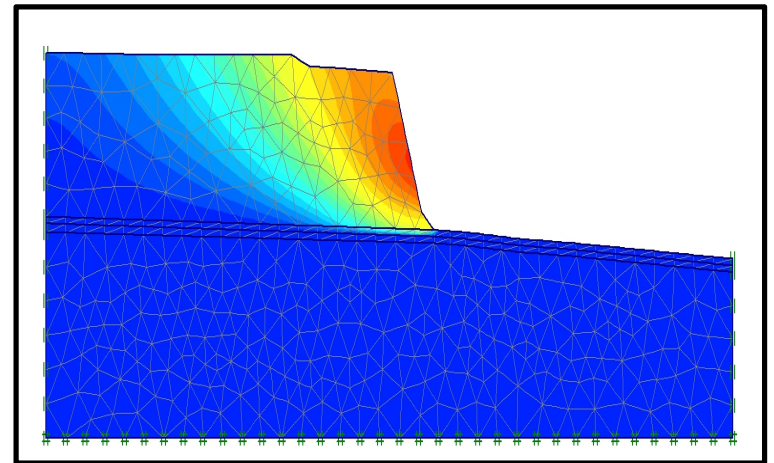

Gambar 10. Hasil Plaxis Potongan East ( $S-W$ Section), model collapse SF $<1,0$

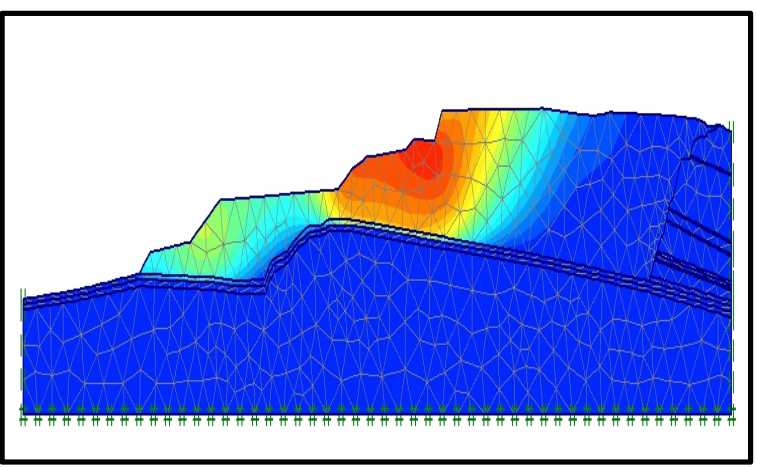

Gambar 11. Hasil Plaxis Potongan West (S-W Section) $\mathrm{SF}=2,34$

\section{Potongan East HW-LW (N-S Section)}

Section $N-S$, juga dibagi atas dua potongan yaitu potongan HW dan potongan LW. Hasil perhitungan Plaxis untuk kedua model ini menunjukkan nilai angka keamanan lereng SF= 1,98 dan SF = 1,33. dimana lereng cukup kuat dan stabil terhadap gaya yang mendorongnya. Hasil permodelan masing-masing ditunjukkan pada Gambar 12 dan Gambar 13.

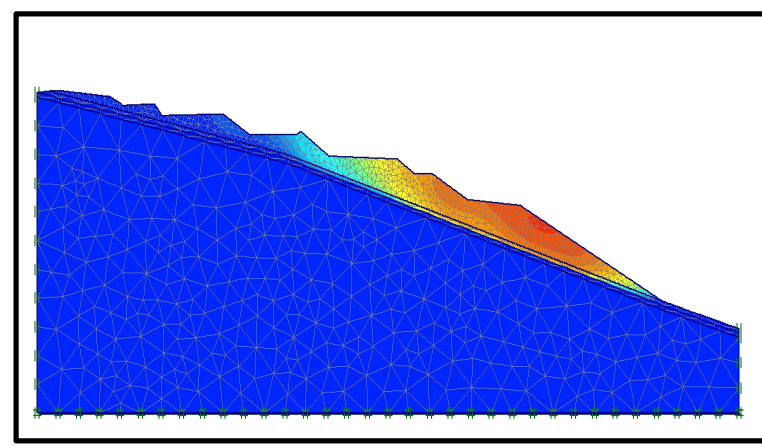

Gambar 12. Hasil Plaxis Potongan East HW (N$S$ Section) $\mathrm{SF}=1,98$ 


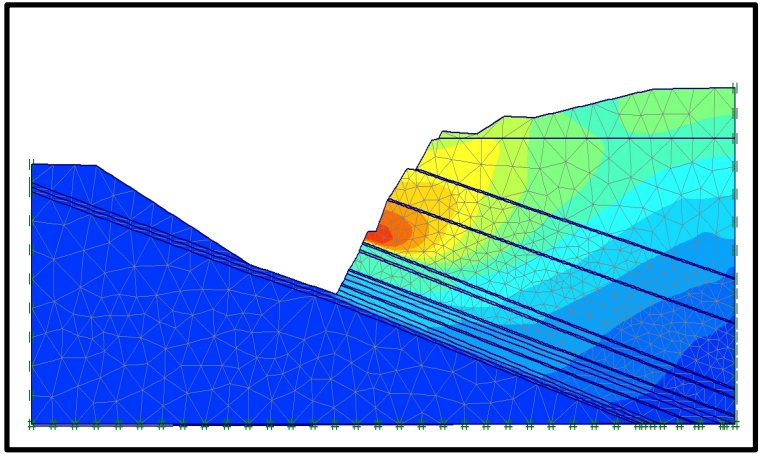

Gambar 13. Hasil Plaxis Potongan East $L W(N-$ $S$ Section) $\mathrm{SF}=1,33$

Setelah dilakukan analisis menggunakan model Plaxis diperoleh hasil sebagai berikut:

1. Analisis untuk potongan east (S-W Section), model telah collapse (runtuh) dengan angka keamanan $\mathrm{SF}<1,0$, karena Plaxis tidak bisa menghitung angka keamanan yang kecil dari nol. Sehingga tidak diketahui berapa SF yang sesungguhnya. Hal ini juga sesuai dengan analisis yang dilakukan menggunakan Slope-W dimana angka keamanan $\mathrm{SF}<1,0(0,114)$.

2. Untuk 3 section lainnya menunjukkan nilai angka keamanan yang lebih besar dari $S F=1,25$, sehingga lereng cukup aman dan stabil.

3. Untuk section dimana angka keamanan kecil dari 1,0, dapat dilakukan beberapa metode perbaikan dengan cara yang dijelaskan pada bab berikut.

Kemantapan (stabilitas) lereng merupakan suatu faktor yang sangat penting dalam pekerjaan yang berhubungan dengan penggalian dan penimbunan tanah, batuan, dan bahan galian karena menyangkut persoalan keselamatan manusia (pekerja), keamanan peralatan serta kelancaran produksi. Keadaan ini berhubungan dengan bermacammacam jenis pekerjaan, misalnya pada pembuatan jalan, tanggul, bendungan, penggalian kanal, penggalian untuk konstruksi, penambangan, dan lain-lain.

Dalam operasi penambangan masalah kemantapan lereng ini akan diketemukan pada penggalian tambang terbuka, bendungan untuk cadangan air kerja, tempat penimbunan limbah buangan (tailing disposal) dan penimbunan bijih (stockyard). Apabila lereng-lereng yang terbentuk sebagai akibat dari proses penambangan (pit slope) maupun yang merupakan sarana penunjang operasi penambangan tidak stabil, maka akan mengganggu kegiatan produksi. Gangguan terhadap kestabilan terjadi bilamana tahanan geser tanah tidak dapat mengimbangi gayagaya yang menyebabkan gelincir pada bidang longsor. Lereng buatan tanah asli / lereng galian (Cut Slope) dibuat dari tanah asli dengan memotong kemiringan. Untuk menyelesaikan masalah ini berdasarkan pengamatan di lapangan dan analisis kestabilan lereng dengan mengunakan Program Plaxis 2D dan Slope-W (kajian terdahulu) maka perlu dilakukan langkah-langkah sebagai berikut:

- Memperkecil gaya yang mendorong lereng untuk terjadi keruntuhan seperi memperkecil ketinggian lereng atau membuat lereng agar lebih datar.

- Memperbesar gaya yang menahan lereng dengan menambahkan counterweight pada kaki lereng atau dengan membuat drainase horizontal untuk mengurangi tekanan air pori.

- Menambahkan perkuatan seperti injeksi dengan grouting, membuat dinding penahan tanah ataupun dengan sheetpile.

\section{KESIMPULAN}

Berdasarkan analisis Consultant Satui Engineering dengan menggunakan program Slope-W untuk Potongan East (S-W Section), Potongan West (S-W Section), Potongan East $H W$ (N-S Section), Potongan East LW (N-S Section) diperoleh model keruntuhan (collapse) dengan angka keamanan SF $<1,0$ dan dibandingkan dengan analisis penulis dengan menggunakan Plaxis-2D, dimana nilai angka keamanan SF $<1$ tidak bisa ditentukan. Berdasarkan analisis Slope-W diperoleh nilai $\mathrm{SF}<1,0(0,114)$ dan analisis Plaxis diperoleh nilai $\mathrm{SF}<1$ terjadi pada Potongan East ( $S-W$ Section), hal ini menunjukan bahwa Analisis dengan program Slope-W dan program Plaxis 2D mempunyai hasil yang sama dalam menentukan kemungkinan akan terjadi keruntuhan pada tanggul yang dibuat untuk menampung air sebagai sumber air. Untuk 3 potongan lainnya menunjukkan nilai angka keamanan yang lebih besar dari $S F=1,25$, sehingga lereng cukup aman dan stabil. Upaya yang perlu dilakukan pada lereng yang berpotensi mengalami kelongsoran dengan memperkuat lereng yang rentan mengalami longsor.

\section{DAFTAR PUSTAKA}

Bria, K. dan Ag. Isjudarto. 2016. Analisa Kestabilan Lereng Pada Tambang 
Batubara terbuka PIT D Selatan Kabupaten Kartanegara Propinsi Kalimantan Timur. Jurnal STTN.

Dwiatmoko, M., S. Melati, A. Sibarani. 2020. Analisis Kestabilan Lereng Bekas Tanah Urug Kota Banjar Baru Kalimantan Selatan, Jurnal Geosapta, 6(1): 69-72.

Jacob. F. and T. Belytschko. 2007. A First Course in Finite Elements. West Sussex, England: John Wiley \& Sons Ltd.

Nuryanto dan S. Wulandari.2017. Analisis Stabilitas Lereng dengan Metoda Keseimbangan Batas dan Elemen Hingga, Jurnal Desain Konstruksi, 16(1): 56-66.

PLAXIS Versi 8.2, Geotechnical Software, Delft Netherlands.2002.

P.T. Arutmin Indonesia 2004, Laporan Studi Kemantapan Lereng Tambang Batubara Reservoir Antasena.

Solihin dan R. Raditia. 2016. Analisis Stabilitas Lereng Tambang Terbuka Bahan Galian C daerah Batujajar di Tegalega Kab Bogor Jawa Barat, Jurnal Teknologi, 1(27): 36-46.

Tinambunan, F. Fahraini, dan Irvani. 2018. Analisis Kestabilan Lereng Menggunakan Metoda Fellenius secara Manual dan Software Slide Roscience 6.0, Jurnal Mineral, 3(1): 1-8.

Violeta, G., A. E. Turangan, dan O.B.A. Sompie. 2014. Analisis Kestabilan Lereng dengan Metoda Fellenius, Jurnal Sipil Statistik, 2(1): 37-46.

Wibowo, S., M. Rinaldi, M.A. Azzam, Z. Zakaria, dan I. Shopian. 2018. Kajian Kestabilan Lereng Batuan Menggunakan Klasifikasi Massa Batuan Metoda Elemen Hingga Analisis Batuan Jatuh, Padjadjaran Geoscience Journal, 2(5): 364-375. 